\title{
Lipid Abnormalities in Untreated Maturity-Onset Diabetics and the Effect of Treatment
}

\author{
R. W. Simpson, J. I. Mann, T. D. R. Hockaday, J. M. Hockaday, R. C. Turner, and R. Jelfs \\ Department of the Regius Professor of Medicine, Radcliffe Infirmary, Oxford, \\ and Department of Social and Community Medicine, University of Oxford, Oxford, England
}

\begin{abstract}
Summary. Plasma cholesterol and serum triglyceride levels and frequency of lipoprotein abnormalities were investigated in 126 untreated maturity-onset diabetics and 126 age- and sexmatched control subjects. Serum triglyceride levels were higher (mean: $1.67 \mathrm{mmol} / \mathrm{l}$ ) and type IV hyperlipoproteinaemia occurred more frequently $(16.7 \%)$ in the diabetic group as compared with the controls $(1.29 \mathrm{mmol} / 1$ and $4.8 \%$ respectively). These findings were not explained by an excessive frequency of renal disease, hypertension or drug treatment amongst the diabetics. Normal men showed higher serum triglyceride (mean: $1.36 \mathrm{mmol} / \mathrm{l}$ ) and lower plasma cholesterol (mean: $5.6 \mathrm{mmol} / \mathrm{l}$ ) levels than normal women $(1.21 \mathrm{mmol} / 1$ and $6.4 \mathrm{mmol} / \mathrm{l}$ respectively). No sex difference was seen amongst the diabetics. Triglyceride levels fell after one month of dietary treatment but only remained lowered in diabetics who required sulphonylureas for glycaemic control. After treatment for one year the correlation between serum triglycerides and blood glucose rose from $r=0.15$ (NS) before treatment to $r=0.43(p<0.001)$. Similarly the correlation between serum triglycerides and ponderal index rose from $r=0.19(\mathrm{NS})$ to $r=0.28$ $(\mathrm{p}<0.02)$.
\end{abstract}

Key words: Untreated maturity-onset diabetes, plasma cholesterol, serum triglyceride, lipoproteins, ponderal index, blood glucose, diet, sulphonylureas.

Although a disturbance in lipoprotein metabolism is a feature of diabetes mellitus, the extent and form of this perturbation is still uncertain. It is generally accepted that marked hyperlipidaemia $[1,2,3,4]$ (type IV or V hyperlipoproteinaemia) [5] occurs in the severe metabolic disturbance associated with hyperglycaemia in insulin-requiring diabetics. The situation in maturity-onset diabetics with moderate hyperglycaemia is less clear.
A number of uncontrolled studies $[6,7,8]$ have reported a wide spectrum of lipoprotein abnormalities in adult diabetics. A recent controlled study [9] in Pima Indians observed increased very low density lipoprotein (V. L. D. L.) triglyceride and low density lipoprotein (L.D.L.) cholesterol, and reduced high density lipoprotein (H.D. L.) cholesterol levels in untreated diabetics while another [10] in Europeans found a similar prevalence of lipoprotein abnormalities in new diabetics and controls. Many of these studies involved heterogenous groups of patients and have not considered the influence of drugs [11], hypertension [12], uraemia [13] or sex $[14,15,16]$, which all affect lipid levels in non-diabetics.

We have investigated fasting plasma cholesterol and serum triglyceride concentrations and the frequency of lipoprotein abnormalities in untreated maturity-onset diabetics and controls. We have tried to take into account the factors known to influence lipid levels and, in addition, a comparison has been made of the effects on lipid abnormalities of different forms of antidiabetic treatment.

\section{Patients}

\section{Untreated Diabetics}

Diabetics 1: This group consisted of 126 patients (64 men, 62 women, in a long term prospective study into diabetes mellitus) [17] with newly diagnosed and untreated diabetes. The patients gave informed consent to the study, were all under 66 years of age and clinically free from any co-existent major illness, including other endocrine, hepatic, myocardial or cerebrovascular disease. They were all initially assessed in outpatients and placed on a diet containing at least $200 \mathrm{~g}$ of carbohydrate per day for three days prior to undergoing an intravenous GTT $\left(20 \mathrm{~g}\right.$ glucose $/ \mathrm{m}^{2}$ body surface). The glucose disappearance rate $\mathrm{Kg}\left(=70 / t_{1 / 2}, t_{1 / 2}=\right.$ number of minutes required for the blood glucose to fall $50 \%$ from its level at $10 \mathrm{~min}$ after glucose administered intravenously) [18], was calculated. A hundred and eighteen patients were unequivocally diabetic on the usual criterion of a $\mathrm{Kg}$ value below $1 \%$ / minute. The remaining eight had equivocal $\mathrm{Kg}$ values between $1 \%$ 
and $1.5 \% / \mathrm{min}$, but were considered to be diabetic because of elevated fasting or random blood glucose levels.

Diabetics 2: This subgroup consisted of 65 of the 126 patients (Diabetics 1) who were normotensive (blood pressure; systolic $<160 \mathrm{~mm} \mathrm{Hg}$, diastolic $<100 \mathrm{~mm} \mathrm{Hg}$ ), non-uraemic (urea $<6.0 \mathrm{mmol} / \mathrm{l}$ ) and not receiving any prescribed medication. Of the excluded patients 49 had raised blood pressure, 13 were receiving diuretics, 11 antidepressants, 7 the contraceptive pill and 5 betablockers or other antihypertensive agents.

\section{Controls 1}

One hundred and twenty six healthy people participating in local screeening programmes who matched the patients in Diabetics 1 for age and sex were randomly selected to be the control group. None of these subjects were hypertensive, uraemic or receiving any prescribed medication. Clinically they were also free of any endocrine or hepatic disease.

\section{Controls 2}

From the larger group of normals (Controls 1), 65 were randomly age- and sex-matched with the diabetic subgroup (Diabetics 2).

\section{Treated Diabetics}

After the diagnosis had been confirmed the patients were randomly allocated into either a low carbohydrate or a low fat dietary regime [17]. The number of calories in the diet was determined by each patient's deviation from desirable body weight (Metropolitan Life Insurance Company Tables). The scale employed was for $>30 \%$ deviation from ideal body weight $1,000 \mathrm{kcal}$ daily, $20-30 \%$ $1,500 \mathrm{kcal}, 10-20 \% 2,000 \mathrm{kcal}$ and for $<10 \%$ a daily calorie intake judged to be suitable for level of activity and age. Patients were seen regularly in outpatients and the dietary advice was reinforced by another consultation with the dietitian one month after entering the study. Compliance of the patient was shown by the good fall in body weight observed after one month which was mostly maintained at one year. Patients were retested fasting, at one month and then at one year without change in their dietary advice. Antidiabetic drugs were recommended during the 12month period according to normal clinical criteria. After one year 35 patients (18 on low carbohydrate and 17 on low fat diets: 19 men, 16 women; average age $53.1 \pm 1.6$ years) had been started on sulphonylurea drugs (SU Diabetics). From the remaining patients on diet alone after one year, 35 diabetics (D Diabetics) were randomly matched for age (average $51.8 \pm 1.9$ ), sex and dietary advice (18 low carbohydrate and 17 low fat diets) with the SU group.

\section{Methods}

Established laboratory methods were used for the analysis of plasma cholesterol [19], serum triglycerides [20], and blood glucose [21]. Lipoprotein types were classified as recommended by the World Health Organization [22]. The upper limits of normal for serum triglycerides and plasma cholesterol were defined as either the mean plus two standard deviations of the controls' values or the age related upper limits as described by Fredrickson et al. [23]. The characterisation of the hyperlipoproteinaemia was confirmed by electrophoresis [24] or by heparin-manganese and sodium dodecylsulphate precipitation techniques [25]. Weight has been expressed relative to height as a ponderal index $\left(\frac{\text { weight }}{\text { height }^{2}}\right)$.

Statistical tests employed were Student's paired and non-paired ' $t$ ' tests, Mann-Whitney $U$ and Wilcoxon matched pairs tests for the non-parametric triglyceride data, and Chi-squared test. Results are expressed as mean \pm standard error of the mean $(\overline{\mathrm{x}} \pm \mathrm{SEM})$.

\section{Results}

\section{Comparison between Diabetics and Normals}

Both diabetic groups were significantly heavier and had significantly higher fasting blood glucose levels than their respective controls (Table 1). Serum triglyceride levels were significantly higher in both groups of diabetics than in the normal control subjects. Amongst men of the two diabetic and control groups the plasma cholesterol levels were similar, whilst female diabetics showed significantly lower levels than their matched controls. Thus a significant sex difference in plasma cholesterol values existed in both control groups but not in either diabetic group. Men of Controls 1 had significantly higher serum triglyceride values than women but this was not so in Controls 2 where women were older than the men. There was no sex difference in serum triglyceride levels in either diabetic group.

The frequency of lipoprotein abnormalities was greater amongst the diabetic than the control subjects using for both lipids, either the upper limits derived from the normals (mean + two standard deviations) (Table 2) or the Fredrickson age-related upper limits of normal [23] (Table 3). This difference was due to an excessive prevalence of type IV hyperlipoproteinaemia in both diabetic groups. There was no difference between Diabetics 1 and 2.

By using the age-related upper limits of normal for both lipids to define lipoprotein abnormalities neither Controls 1 nor either diabetic group showed significant sex differences in lipoprotein patterns (Table 3). In Controls 2, women had a higher incidence of type II abnormalities, although it was not possible to separate this finding from the effect of age differences on lipoproteins.

Low, but significant correlations were found in diabetics $(\mathrm{r}=0.23, \mathrm{p}<0.02)$ and controls $(\mathrm{r}=$ $0.23, p<0.02$ ) between serum triglyceride levels and ponderal index. Neither of the two diabetic groups nor the two control groups showed any correlation between serum triglyceride and blood glucose levels. Only the control subjects showed a significant $(\mathrm{r}=$ $0.27, \mathrm{p}<0.01$ ) correlation between blood glucose and ponderal index.

\section{Effect of Treatment}

Ponderal index, blood glucose, serum triglyceride and plasma cholesterol values for both treatment groups are shown in Table 4. At the time of diagnosis the group in whom sulphonylureas were subsequently started after a variable period on diet treatment alone, differed significantly in blood glucose 
Table 1. Ponderal index, blood glucose, serum triglyceride and plasma cholesterol levels in diabetic and control subjects

\begin{tabular}{|c|c|c|c|c|c|c|c|c|}
\hline & \multicolumn{2}{|c|}{$\begin{array}{l}\text { Controls } 1 \\
(126)\end{array}$} & \multicolumn{2}{|c|}{$\begin{array}{l}\text { Diabetics } 1 \\
\quad(126)\end{array}$} & \multicolumn{2}{|c|}{$\begin{array}{l}\text { Controls } 2 \\
\quad(65)\end{array}$} & \multicolumn{2}{|c|}{$\begin{array}{l}\text { Diabetics } 2 \\
(65)\end{array}$} \\
\hline & $\begin{array}{c}\text { Males } \\
(64)\end{array}$ & $\begin{array}{l}\text { Females } \\
\quad(62)\end{array}$ & $\begin{array}{c}\text { Males } \\
(64)\end{array}$ & $\begin{array}{l}\text { Females } \\
\quad(62)\end{array}$ & $\begin{array}{l}\text { Males } \\
(38)\end{array}$ & $\begin{array}{l}\text { Females } \\
\quad(27)\end{array}$ & $\begin{array}{l}\text { Males } \\
(38)\end{array}$ & $\begin{array}{l}\text { Females } \\
\text { (27) }\end{array}$ \\
\hline \multirow{2}{*}{ Age - years } & $52 \pm 1$ & $52 \pm 1$ & $51 \pm 1$ & $51 \pm 1$ & $47 \pm 2$ & $52 \pm 1^{a}$ & $45 \pm 2$ & $52 \pm 1^{a}$ \\
\hline & \multicolumn{2}{|c|}{$52 \pm 1$} & \multicolumn{2}{|c|}{$51 \pm 1$} & \multicolumn{2}{|c|}{$49 \pm 1$} & \multicolumn{2}{|c|}{$48 \pm 1$} \\
\hline \multirow{2}{*}{$\begin{array}{l}\text { Ponderal Index } \\
\text { kg. } \mathrm{cm}^{-2}\end{array}$} & $2.46 \pm \underbrace{0.04}$ & $2.50 \pm 0.05$ & $2.65 \pm \underbrace{0.05}$ & $2.94 \pm 0.08^{\mathrm{b}}$ & $2.42 \pm \underbrace{0.04}$ & $2.47 \pm 0.06$ & $2.55 \pm \underbrace{0.11}$ & $2.84 \pm 0.07^{\mathrm{a}}$ \\
\hline & \multicolumn{2}{|c|}{$2.48 \pm 0.03$} & \multicolumn{2}{|c|}{$2.79 \pm 0.05^{\mathrm{b}}$} & \multicolumn{2}{|c|}{$2.44 \pm 0.04$} & \multicolumn{2}{|c|}{$2.67 \pm 0.06^{\mathrm{b}}$} \\
\hline \multirow{2}{*}{$\begin{array}{l}\text { Blood glucose } \\
\mathrm{mmol} / 1\end{array}$} & $4.9 \pm \underbrace{0.1}$ & $5.1 \pm 0.1$ & $11.7 \pm \underbrace{0.5}$ & $12.3 \pm 0.5$ & $4.8 \pm \underbrace{0.1}$ & $4.8 \pm 0.1$ & $10.5 \pm \underbrace{0.6}$ & $12.4 \pm 0.8^{\mathrm{a}}$ \\
\hline & \multicolumn{2}{|c|}{$5.0 \pm 0.1$} & \multicolumn{2}{|c|}{$12.0 \pm 0.4^{\mathrm{b}}$} & \multicolumn{2}{|c|}{$4.8 \pm 0.1$} & \multicolumn{2}{|c|}{$11.3 \pm 0.5^{b}$} \\
\hline \multirow{2}{*}{$\begin{array}{l}\text { Serum triglyceride } \\
\mathrm{mmol} / 1\end{array}$} & $1.36 \pm \underbrace{0.06}$ & $1.21 \pm 0.06^{\mathrm{a}}$ & $1.79 \pm \underbrace{0.15}$ & $1.54 \pm 0.11$ & $1.24 \pm \underbrace{0.06}$ & $1.30 \pm 0.10$ & $1.75 \pm \underbrace{0.20}$ & $2.01 \pm 0.31$ \\
\hline & \multicolumn{2}{|c|}{$1.29 \pm 0.04$} & \multicolumn{2}{|c|}{$\underbrace{}_{1.67 \pm 0.09^{b}}$} & \multicolumn{2}{|c|}{$1.27 \pm 0.06$} & \multicolumn{2}{|c|}{$1.86 \pm 0.17^{b}$} \\
\hline \multirow{2}{*}{$\begin{array}{l}\text { Plasma cholesterol } \\
\mathrm{mmol} / \mathrm{l}\end{array}$} & $5.6 \pm \underbrace{0.2}$ & $6.4 \pm 0.2^{b}$ & $5.6 \pm \underbrace{0.2}$ & $5.4 \pm 0.2$ & $5.3 \pm \underbrace{0.2}$ & $6.6 \pm 0.4^{b}$ & $5.4 \pm \underbrace{0.2}$ & $5.3 \pm 0.2$ \\
\hline & $6.0 \pm$ & $=0.1$ & $5.5 \pm$ & $=0.1^{b}$ & 5.8 & 0.2 & 5.4 & 0.2 \\
\hline
\end{tabular}

Comparisons are shown between the sexes within each group and between the paired groups of untreated diabetics and controls. Diabetics 1 consists of newly diagnosed patients $<66$ years old and clinically free of any co-existent major illness. Controls 1 are age- and sexmatched normotensive, non-uraemic normal subjects not receiving any prescribed medication. Diabetics 2 are a subgroup of Diabetics 1 who are normotensive, non-uraemic and not receiving any prescribed medication. Controls 2 are a subgroup of Cohtrols 1 who are age- and sex-matched with Diabetics 2. Values shown are mean \pm SEM. Numbers of subjects in parentheses Mann-Whitney " $U$ " test for triglycerides, Student's " $t$ " test for others

${ }^{a} \mathrm{p}<0.05{ }^{\mathrm{b}} \mathrm{p}<0.01$

levels $(\mathrm{p}<0.005)$ from those who remained on diet alone. They did not differ significantly in ponderal index or circulating lipid levels. Serum triglyceride concentration fell significantly in both groups over the first month but only the SU patients maintained this improvement over the year. In contrast, both groups showed a significant fall in plasma cholesterol over the initial month which was maintained for 12 months. Weight fell significantly in both groups by one month but this change was only maintained in $\mathrm{D}$ diabetics and by one year both groups had similar weights. During the first month blood glucose levels declined in both groups and by one year, although the diabetics in the SU group had fallen further $(\mathrm{p}<0.005)$, the D patients still had significantly $(p<0.05)$ lower values than the SU diabetics.

After one year both the patients receiving the modified fat and low carbohydrate diets for each treatment group showed significant falls in plasma glucose. Both dietary groups of the $\mathrm{D}$ patients showed a significant fall ( $p<0.001$ low carbohydrate, $\mathrm{p}<0.05$ low fat) in ponderal index after 12 months while neither dietary group showed a significant change amongst the SU patients. Only the patients receiving the modified fat diet for both treatment groups (D p $<0.01$, Su $\mathrm{p}<0.01$ ) showed a significant fall in cholesterol over the year. The fall in serum triglycerides persisting for 1 year in the $\mathrm{Su}$
Table 2. Number and percentage of individuals with lipoprotein abnormalities defined by upper limits of normal derived from the control subjects

\begin{tabular}{|c|c|c|c|c|c|}
\hline & & $\begin{array}{l}\text { Con- } \\
\text { trols } 1 \\
\mathbf{n}=126\end{array}$ & $\begin{array}{l}\text { Dia- } \\
\text { betics } 1 \\
n=126\end{array}$ & $\begin{array}{l}\text { Con- } \\
\text { trols } 2 \\
\mathrm{n}=65\end{array}$ & $\begin{array}{l}\text { Dia- } \\
\text { betics } 2 \\
n=65\end{array}$ \\
\hline \multirow{4}{*}{ 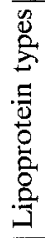 } & Normal & 116 & 104 & 61 & 54 \\
\hline & IV & 6 & 21 & 3 & 10 \\
\hline & II b & 1 & 0 & 1 & 0 \\
\hline & II a & 3 & 1 & 0 & 1 \\
\hline$\%$ & abnormal & $7.9 \%$ & $17.5 \%{ }^{\mathrm{a}}$ & $6.2 \%$ & $16.9 \%^{\mathrm{a}}$ \\
\hline
\end{tabular}

Comparison between paired groups of controls and diabetics. Groups are as defined in Table 1

Upper limits of normal (mean $+2 \mathrm{SD}$ ): Serum triglycerides: Males $2.38 \mathrm{mmol} / \mathrm{l}$, Females $2.15 \mathrm{mmol} / \mathrm{l}$. Plasma cholesterol: Males $8.0 \mathrm{mmol} / 1$, Females $10.2 \mathrm{mmol} / 1$

Chi-squared test: ${ }^{a} \mathrm{p}<0.001$

patients was only statistically significant amongst the low carbohydrate patients $(\mathrm{p}<0.05)$. However, the trend for the low fat group was in the same direction.

Neither treatment group individually nor together showed a significant correlation before treatment between serum triglycerides and ponderal index (D + SU groups $r=0.19, p=N S$ ) or blood 
Table 3. Number and percentage of individuals with lipoprotein abnormalities defined by Fredrickson's age adjusted upper limits of normal [23]

\begin{tabular}{|c|c|c|c|c|c|c|c|c|}
\hline & \multicolumn{2}{|c|}{ Controls 1} & \multicolumn{2}{|c|}{ Diabetics 1} & \multicolumn{2}{|c|}{ Controls 2} & \multicolumn{2}{|c|}{ Diabetics 2} \\
\hline & Male & Female & Male & Female & Male & Female & Male & Female \\
\hline \multirow[t]{2}{*}{ Normal } & $\underbrace{56}$ & 52 & 42 & 46 & $\underbrace{35}$ & 21 & $\underbrace{24}$ & 21 \\
\hline & \multicolumn{2}{|c|}{108} & \multicolumn{2}{|c|}{88} & \multicolumn{2}{|c|}{56} & \multicolumn{2}{|c|}{45} \\
\hline \multirow[t]{2}{*}{ IV } & $\underbrace{7}$ & 5 & $\underbrace{20}$ & 14 & $\underbrace{3}$ & 4 & 13 & 5 \\
\hline & \multicolumn{2}{|c|}{12} & \multicolumn{2}{|c|}{34} & \multicolumn{2}{|c|}{7} & \multicolumn{2}{|c|}{18} \\
\hline \multirow[t]{2}{*}{ IIb } & $\underbrace{0}$ & 1 & 1 & 0 & $\underbrace{0}$ & 1 & $\underbrace{0}$ & 0 \\
\hline & \multicolumn{2}{|c|}{1} & \multicolumn{2}{|c|}{1} & \multicolumn{2}{|c|}{1} & \multicolumn{2}{|c|}{0} \\
\hline \multirow[t]{2}{*}{ II a } & $\underbrace{1}$ & 4 & $\underbrace{1}$ & 2 & $\underbrace{0}$ & 1 & 1 & 1 \\
\hline & \multicolumn{2}{|c|}{5} & \multicolumn{2}{|c|}{3} & \multicolumn{2}{|c|}{1} & \multicolumn{2}{|c|}{2} \\
\hline \multirow[t]{2}{*}{$\%$ Abnormal } & 12.5 & 16.1 & 34.4 & 25.8 & 7.9 & $22.2^{\mathrm{a}}$ & 36.8 & 22.2 \\
\hline & \multicolumn{2}{|c|}{14.3} & \multicolumn{2}{|c|}{$30.2^{b}$} & \multicolumn{2}{|c|}{13.8} & \multicolumn{2}{|c|}{$30.8^{b}$} \\
\hline
\end{tabular}

Comparisons are shown between the sexes within each group and between paired groups of controls and diabetics

Chi-squared test: ${ }^{\mathrm{a}} \mathrm{p}<0.01{ }^{\mathrm{b}} \mathrm{p}<0.001$

Table 4. Ponderal index, blood glucose, serum triglyceride and plasma cholesterol levels at diagnosis and at 1 month and 12 months in patients treated by diet alone (D) or in conjunction with sulphonylureas (SU)

\begin{tabular}{|c|c|c|c|c|c|c|}
\hline & \multicolumn{2}{|l|}{ At diagnosis } & \multicolumn{2}{|l|}{1 month } & \multicolumn{2}{|l|}{12 months } \\
\hline & $D(n=35)$ & $\mathrm{SU}(\mathrm{n}=\mathbf{=} 35)$ & $\mathrm{D}$ & SU & D & SU \\
\hline $\begin{array}{l}\text { Ponderal index } \\
\text { kg. } \mathrm{cm}^{-2}\end{array}$ & $2.81 \pm 0.08$ & $2.66 \pm 0.08$ & $2.66 \pm 0.08^{\mathrm{c}}$ & $2.60 \pm 0.08^{\mathrm{c}}$ & $2.60 \pm 0.08^{\mathrm{c}}$ & $2.66 \pm 0.09$ \\
\hline $\begin{array}{l}\text { Blood glucose } \\
\mathrm{mmol} / 1\end{array}$ & $9.8 \pm 0.6$ & $14.1 \pm 0.6$ & $7.2 \pm 0.3^{\mathrm{c}}$ & $11.1 \pm 0.6^{c}$ & $7.2 \pm 0.5^{\mathfrak{c}}$ & $8.4 \pm 0.5^{c}$ \\
\hline $\begin{array}{l}\text { Serum triglyceride } \\
\mathrm{mmol} / 1\end{array}$ & $1.60 \pm 0.19$ & $1.45 \pm 0.12$ & $1.26 \pm 0.08^{\mathrm{a}}$ & $1.15 \pm 0.09^{\mathrm{b}}$ & $1.52 \pm 0.11$ & $1.20 \pm 0.10^{\mathrm{a}}$ \\
\hline $\begin{array}{l}\text { Plasma cholesterol } \\
\mathrm{mmol} / 1\end{array}$ & $5.67 \pm 0.21$ & $5.30 \pm 0.21$ & $4.71 \pm 0.21^{\mathrm{c}}$ & $5.00 \pm 0.16^{\mathrm{a}}$ & $5.11 \pm 0.43^{b}$ & $4.90 \pm 0.44^{c}$ \\
\hline
\end{tabular}

Comparisons are shown between the changes from diagnosis to one month and diagnosis to 12 months within each treatment group. All values given as mean $\pm S E M$

Wilcoxon matched pairs test for serum triglycerides and Student's paired " $t$ " test for others

${ }^{\mathrm{a}} \mathrm{p}<0.05{ }^{\mathrm{b}} \mathrm{p}<0.01^{\mathrm{c}} \mathrm{p}<0.001$

glucose $(\mathrm{D}+\mathrm{SU}$ groups $\mathrm{r}=0.15, \mathrm{p}=\mathrm{NS})$. After one year of treatment both groups showed a significant correlation between serum triglyceride levels and blood glucose (D group $\mathrm{r}=0.57, \mathrm{p}<0.001, \mathrm{SU}$ group $r=0.45, p<0.001, D+S U$ groups $r=0.43$, $\mathrm{p}<0.001$ ). Individually neither group at 12 months showed a correlation between serum triglycerides and ponderal index, although when both were examined together a low but significant correlation was found $(r=0.28, p<0.02)$. At no stage was a correlation found between ponderal index and blood glucose.

The overall frequency of lipoprotein abnormalities defined by upper limits of normal for both lipids derived from the controls was $17.1 \%$ at diagnosis and fell to $7.1 \%$ by one year $(\mathrm{p}<0.05)$. Both treatment groups behaved similarly, neither individually showing a significant fall after 12 months (D patients $17.1 \%$ to $8.6 \% \mathrm{p}=\mathrm{NS}$; SU patients $17.1 \%$ to $5.7 \% \mathrm{p}=\mathrm{NS}$ ).

\section{Discussion}

Disordered lipid metabolism in diabetics has aroused particular interest because of the association between hyperlipidaemia and cardiovascular disease. It is not clear whether the increased frequency of arteriosclerotic disease in diabetics is a consequence of the lipid or carbohydrate abnormality. We wished to clarify the abnormality of lipid metabolism which occurs in untreated maturity-onset diabetics. We found serum triglyceride levels to be higher amongst diabetics than controls. This contrasts with a recent finding [10] in untreated European patients but is in agreement with another in Pima Indians [9] and 
other uncontrolled observations in treated adult patients $[4,26]$. Plasma cholesterol levels amongst diabetic men and controls were similar but in diabetic women values were lower than controls. Previous workers have found cholesterol levels to be elevated in Pima Indian diabetics [9], normal in untreated $[10]$, and elevated $[4,26]$ in treated predominantly European diabetics. The reasons for these differences in Caucasian patients are not clear and are difficult to examine because most previous workers have not considered the sexes separately.

Our observations of lower total plasma cholesterol but higher serum triglycerides in normal men, compared with women during the sixth decade, are consistent with earlier reports $[14,15,16]$. In agreement with previous findings [7,27], a sex difference was not observed in either diabetic group although there was an age difference in the selected patients.

Our study shows, using either set of criteria for defining upper limits of normal for lipids, a very definite increase of lipoprotein abnormalities in untreated maturity-onset patients. Using Fredrickson [23] age-related upper limits of normal other workers have reported a similar incidence of hyperlipoproteinaemia for treated [8] and untreated adult diabetics $[7,10]$. The increase in this study and others $[7,8]$ has been due largely to increased numbers of patients with the type IV pattern. These findings contrast very sharply with an uncontrolled study by Hayes [6] where he reported an overall frequency of abnormal lipoproteins in untreated mature patients of $67.9 \%$, with $19.8 \%$ showing type III. Both the frequency of total lipoprotein abnormalities which is much greater than that found in the present report and by other workers $[7,8,10]$ and the incidence of type III which is exceedingly rare in non-diabetics [14] are difficult to explain. Ballantyne et al. [10], in a controlled study using Fredrickson criteria [23], found abnormalities in about $30 \%$ of both untreated adult diabetics and normals. Whilst we found a similar incidence of abnormalities in both groups of diabetics using the same criteria, only about $14 \%$ of the controls were abnormal. It is not clear from the earlier report [10] whether the controls were normotensive or receiving any medication. Furthermore, these controls were subjects with glycosuria drawn from a diabetic clinic subsequently defined as nondiabetic on the basis of one oral GTT.

There are no universally accepted upper limits of normal for serum triglycerides and plasma cholesterol. The upper limits of normal for the population derived by calculating the mean plus two standard deviations of both triglycerides and cholesterol for normal men and women gave values above those generally accepted as desirable. However, these values did highlight the lipoprotein abnormalities associated with untreated diabetes mellitus. The lower limits of normal defined by Fredrickson [23] may still be higher than the biologically desirable levels since individuals with cholesterol levels of around $300 \mathrm{mg} / 100 \mathrm{ml}(7.8 \mathrm{mmol} / \mathrm{l})$ have an approximately fivefold greater risk of developing ischaemic heart disease than those with cholesterols of around $200 \mathrm{mg} / 100 \mathrm{ml}(5.2 \mathrm{mmol} / \mathrm{l})$ [28].

The pathogenesis of the disordered lipid metabolism is uncertain although many workers consider it to be a direct result of the disturbed carbohydrate metabolism. It is clear that the severe hyperlipidaemia found with poor control in insulin-dependent diabetics is reversed by treatment with insulin $[1,2,3]$. In addition, this and a previous study [6] have shown that the treatment of the moderate hyperglycaemia in untreated maturity onset patients result in a lowering of triglyceride levels and frequency of lipoprotein abnormalities. Despite this concomitance of change in blood glucose, serum triglyceride and ponderal index, before treatment there were poor correlations between all of these parameters. Previous workers [7] have also failed to show a significant correlation between blood glucose and serum triglyceride in untreated patients. These findings suggest that in patients with untreated hyperglycaemia, blood glucose levels and possibly obesity have at the most a small direct role in the genesis of the initial hyperlipidaemia.

The observations that similar plasma glucose falls and weight loss occurred with either type of diet and that the reduction of plasma cholesterol was restricted to the patients receiving the modified fat dietary advice are consistent with our previous findings [17].

Interesting differences emerge when the responses of diabetics to different treatments are considered. Whilst both treatment groups showed a fall in plasma lipid concentration over the first month, only those diabetics who subsequently received sulphonylureas showed continued improvement at one year. The SU diabetics also showed a further fall in blood glucose levels although at this stage they still had higher glucose levels than the diet only patients. This difference is not due to obesity as both groups had similar weights after 12 months of treatment. Nor can it be attributed to differing diets as the two groups were matched for dietary advice and in both dietary groups there was a trend towards lower serum triglycerides at one year. Previous studies $[29,30]$ have also shown a simultaneous fall in blood glucose and triglycerides following the administration of sulphonylureas. The difference in response of the two treatment groups, however, suggests that either sulphonylureas have an additional triglyceride lowering effect or that there is another factor apart from blood glucose levels affecting triglyceride values. 
The observation here and by previous workers [8] of a correlation between blood glucose and triglycerides in treated maturity-onset patients indicates an association between the metabolism of glucose and this lipid after antidiabetic treatment. The low but significant correlation between ponderal index and serum triglyceride levels, but not ponderal index and blood glucose after treatment, suggests that obesity may have an independent long-term effect on triglyceride levels in diabetics.

Acknowledgements. We are greatful to Mrs. C. Whitwell and Mrs. B. Pym for their skilled nursing assistance, to Mrs. H. Dahr for technical assistance, and Drs. J. G. G. Ledingham and J. Gear for help in collecting normal subjetcs. Glucose estimations were kindly performed by Mr. W. Penfold in the Department of Clinical Biochemistry, Radcliffe Infirmary. We gratefully acknowledge the financial support received from the British Diabetic Association and from the International Sugar Research Foundation Inc.

\section{References}

1. Bagdade, J. D., Porte, D., Jr., Bierman, E. L.: Diabetic lipaemia. A form of acquired fat induced lipaemia. N. Engl. J. Med. 276, 427-433 (1967)

2. Chance, G. W., Albutt, E. C., Edkins, S. M.: Serum lipids and lipoproteins in untreated diabetic children. Lancet 1969 I, $1126-1128$

3. Salt, H. B., Wolff, O. H., Nestadt, A., Lloyd, June K.: Control of lipaemia in children with diabetes mellitus. The role of insulin and the effects of a diet rich in unsaturated fatty acids. Lancet 1960 I, 71-75

4. Schrade, W., Boehle, T. N., Biegler, R., Harmuth, E.: Fatty acid composition of lipid fractions in diabetic serum. Lancet 1963 I, 285-290

5. Nikkilä, E. A.: Triglyceride metabolism in diabetes mellitus. Prog. Biochem. Pharmacol. 8, 271-299 (1973)

6. Hayes, T. M.: Plasma lipoproteins in adult diabetes. Clin. Endocrinol. (Oxf.) 1, 247-251 (1972)

7. Rodger, N. W., Du, E. L.: Some factors indicative of hypertriglyceridaemia in patients investigated for diabetes mellitus. Can. Med. Assoc. J. 109, 363-368 (1973)

8. Wilson, D. E., Schreibman, P.H., Day, V.C., Arky, R. A.: Hyperlipidaemia in an adult diabetic population. J. Chronic Dis. 23, 501-506 (1970)

9. Howard, B. V., Savage, P. J., Bennion, L. J., Bennett, P. H.: Lipoprotein composition in diabetes mellitus. Atherosclerosis 30, 153-162 (1978)

10. Ballantyne, D., White, C., Strevens, E. A., Lawrie, T. D. V., Lorimer, A. R., Manderson, W. G., Morgan, H. G.: Lipoprotein concentrations in untreated adult onset diabetes mellitus and the relationship of the fasting plasma triglyceride concentration to insulin secretion. Clin. Chim. Acta 78, 323-329 (1977)

11. Johnson, B., Bye, C., Labrooy, J., Munro-Faure, D., Slack, J.: The relation of antihypertensive treatment to plasma lipids and other vascular risk factors in hypertensives. Clin. Sci. Mol. Med. 47, 9P (1974)

12. Thomas, G. W., Mann, J. I., Beilin, L. J., Ledingham, J. G. G., Wynn, S.: Hypertension and raised serum lipids. Br. Med. J. 1977 II, 805
13. Bagdade, J. D., Porte, D. Jr., Bierman, E. L.: Hypertriglyceridaemia. A metabolic consequence of chronic renal failure. N. Engl. J. Med. 279, 181-185 (1968)

14. Lewis, B., Chait, A., Wootton, I. D. P., Oakley, C. M., Krikler, D. M., Sigurdsson, G., February, A., Maurer, B., Birkhead, J.: Frequency of risk factors for ischaemic heart disease in a healthy British population. Lancet 1974 I, 141-146.

15. Slack, J., Noble, N., Meade, T. W., North, W. R. S.: Lipid and lipoprotein concentrations in 1,604 men and women in working populations in north-west London. Br. Med. J. 1977 II, 353-357

16. Carlson, L. A., Lindstedt, S.: The initial values of plasma lipids. Acta Med. Scand. [Suppl.] 493, 10-11 (1968)

17. Hockaday, T.D. R., Hockaday, J.M., Mann, J. I., Turner, R. C.: A prospective comparison of modified fat - high carbohydrate with standard low-carbohydrate dietary advice in the treatment of diabetes: a one year follow-up study. Br. J. Nutr. 39, 357-362 (1978)

18. Marble, A.: Laboratory procedures useful in diagnosis and treatment. In: Joslins Diabetes Mellitus. Marble, A., White, P., Bradley, R. F., Krall, L. P. (Ed.), pp. 191-208. Philadelphia: Lea and Febiger 1971

19. Searcy, R. L., Bergquist, L. M.: A new colour reaction for the quantitation of serum cholesterol. Clin. Chim. Acta 5, 192-199 (1960)

20. Eggstein, M., Kreutz, F. H.: Eine neue Bestimmung der Neutralfette im Blutserum und Gewebe. Klin. Wochenschr. 44, 262-267 (1966)

21. Technicon Auto-analyzer Manual:: Glucose oxidase (gum guiac) method

22. Beaumont, J. L., Carlson, L. A., Cooper, G. R., Fejfar, Z., Fredrickson, D.S., Strasser, T.: Classification of hyperlipidaemias and hyperlipoproteinaemias. Bull. WHO 43, 891-908 (1970)

23. Fredrickson, D. S., Levy, R. I., Lees, R. S.: Fat transport in lipoproteins - an integrated approach to mechanisms and disorders. N. Engl. J. Med. 276, 148-156 (1967)

24. Noble, R. P.: Electrophoretic separation of plasma lipoproteins in agarose gel. J. Lipid Res. 9, 693-700 (1968)

25. Wilson, D. E., Spiger, M: J., Done, G. A.: A dual precipitation method for quantitative plasma lipoprotein measurement without ultracentrifugation. J. Lab. Clin. Med. 82, 473-482 (1973)

26. New, M. I., Roberts, T. N., Bierman, E. L., Reader, G. G.: The significance of blood lipid alterations in diabetes mellitus. Diabetes 12, 208-212 (1963)

27. Bergqvist, N.: Serum lipids in an ambulatory diabetic clientele. Acta Med. Scand. 187, 213-218 (1970)

28. Kannel, W. B., Castelli, W. P., Gordon, T., McNamara, P. M.: Serum cholesterol, lipoproteins and the risk of coronary heart disease. Ann. Intern. Med. 74, 1-12 (1971)

29. Morris, J. H., West, D. A., Bolinger, R. E.: Effect of oral sulphonylureas on plasma triglycerides in diabetics. Diabetes 13, 87-98 (1964)

30. Holman, R. R., Turner, R. C.: Basal normoglycaemia attained with chlorpropamide in mild diabetes. Metabolism 27, 539-547 (1978)

Received: May 10, 1978,

and in revised form: September 14, 1978

R. W. Simpson

Department of Regius Professor of Medicine

Radcliffe Infirmary

Oxford, England 